\title{
Enflasyon-Faiz Oranı ve Enflasyon-Döviz Kuru İkilemi: GEG Programı Döneminde Türkiye Gerçeği
}

\author{
(Inflation - Interest Rate - Exchange Rate Dilemma: Turkish Reality During \\ The GEG Program)
}

Işı| AKGÜL'1, Selin ÖZDEMIR²

\begin{abstract}
ÖZET
Bu makalede analiz döneminde faiz oranı-enflasyon oranı ile döviz kuru-enflasyon oranı ilişkisi hakkında siyasi söylemler ile Merkez Bankası söylemlerinden hangisinin geçerli olduğunun ortaya çıkarılması amaçlanmıştır. Analiz dönemi Güçlü Ekonomiye Geçiş Programını kapsayacak şekilde 2003 ile 2016 yılları arasıdır. Ayrıca analizler, kırılma tarihlerine uygun olacak şekilde, 2 alt dönem için de yapılmış, enflasyon-faiz oranı ile enflasyondöviz kuru arasındaki nedensellik ilişkisi her dönem incelenmiştir. Anılan ilişkilerin analizi, durağan ancak doğrusal olmadığı çeşitli testlerle belirlenen değişkenler için Diks-Panchenko doğrusal olmayan nedensellik testleri yardımı ile yapılmıştı. Analizler sonucunda her iki söylemin de geçerli olduğu dönemler olduğu gibi, sadece bir söylemin geçerli olduğu dönemlerin olduğu bulgusuna ulaşılmıştır. Bulgular, politika yapıcılara anılan ekonomik değişkenler arasındaki ilişkiyi nasıl ele almaları gerektiği konusunda önemli bilgiler sunmakta ve yol gösterici olacak niteliktedir.
\end{abstract}

Anahtar kelimeler: Enflasyon Oranı, Faiz Oranı, Döviz Kuru, Doğrusal Olmayan Nedensellik, DiksPanchenko Nedensellik Testi

\begin{abstract}
This study aims to bring out whether the Central Bank's or politicians statements are valid on the relationships between both interest rate and inflation rate and exchange rate and inflation rate. Analyzing period covers the period between 2006 and 2013 so as to cover program for Turkey's Transition to Strong Economy. Furthermore analysis are made for two sub-periods in concordance with breakdown dates, and the causality between both interest rate and inflation rate and exchange rate and inflation rate is examined for each sub periods. The analysis of abovementioned relationships for the variables which are determined stationary but non-linear is implemented by Diks-Panchenko nonlinear causality test. After the analysis we find that there are sub-periods in which both two ideas are valid or there are sub-periods only one idea is valid. Findings can be a guide and provide important information to the policy makers how to deal with the relationships between economic variables.
\end{abstract}

Key Words: Inflation Rate, Interest Rate, Exchange Rate, Nonlinear Causality, Diks-Panchenko Causality Test.

\section{GíRiş}

Türkiye'de, 2000'li yılların başından itibaren para politikalarında önemli bir değişim gerçekleşmiş, bu bağlamda fiyat istikrarının kalıcı olmasını sağlamak amacı ile Türkiye Cumhuriyet Merkez Bankası (TCMB), 2002 yılından itibaren örtük, 2006 yılından itibaren de açık olmak üzere enflasyon hedeflemesi rejimini yürütmüştür. Böylece enflasyon beklentilerini düşük seviyelere doğru çekilebilmiş, ancak 2010 yılından itibaren TCMB yeni bir politika bileşeni oluşturarak, para politikası uygulamalarında fiyat istikrarının yanı sıra finansal istikrarı da amaç edinmiştir. Bu dönemde Türkiye'de para politikası uygulamalarındaki değişiklikler, enflasyon ve faiz oranı arasındaki ilişkinin yeniden incelenmesini gerekli hale getirmiştir.

Ayrıca ekonomi teorisinde enflasyonun faiz oranı ile ilişkisi, üzerinde tartışılan ve sıkça araştırılan temel konulardan biri olarak güncelliğini devam ettirmektedir. Bu bağlamda faiz artışının enflasyon oranını yükselttiği tezini savunanlar olduğu gibi, yüksek enflasyonun faizin yükselmesine yol açtığı tezini 
savunanların da var olduğu görülmektedir. Bu gibi konularda tartışmalar her zaman olmuş ve genel bir görüş birliği sağlanamadan süre gitmektedir.

Bunun yanı sıra döviz kuru kaynaklı baskıların doğrudan etkilerin yanında beklentileri de olumsuz yönde etkileyerek enflasyon eğilimini güçlendirdiği gözlenmektedir. Merkez Bankasının hükümete ve kamuoyuna yaptığı son açıklamada da, 2015 yılı enflasyon hedefinin tutturulamamasının temel nedeninin kurlar olduğu belirtilmiştir.

Türkiye gibi küçük ve açık ekonomilerde beklentiler, döviz kurlarındaki değişimlerin enflasyon beklentileri için referans olarak alınmaları nedeniyle kur değişimleri tarafından etkilenebilmektedir; başka bir deyiş ile Türkiye'de enflasyon oranının döviz kuruna duyarlılı̆ı yüksektir. Enflasyon ve döviz kurundaki yükseliş ise faiz oranı artışını gerektirebilir. MB'nın bu göstergeler ışığında davranmaması durumunda ise kur artışı daha da hızlanabilir (Kara ve Öğünç, 2008;52). Bu üç değişken arasındaki ilişki, 2002 yılından itibaren Enflasyon hedeflemesi programı uygulamasına geçen Türkiye için sıklıkla gündeme gelmektedir. Tüm bu bilgiler ışığında, bu makalede faiz oranı, enflasyon ve döviz kuru ilişkisi hakkında yapılan siyasi söylemler ve Merkez Bankasının söylemlerinin geçerliliğini ortaya çıkaracak analizler yapılmaktadır.

Giriş bölümünün ardından ikinci bölümde bu konunun neden seçildiği, makalenin varsayımlarından bahsedilmekte, üçüncü bölümde yazın taraması yapılarak bulguları özetlenmekte ve dördüncü bölümde veri seti tanıtılmakta, verilerin analizi, durağanlık ve doğrusallık testleri yapılmakta ve kullanılan yöntemler hakkında bilgi verilmektedir. Son bölüm, bulguların bir arada ele alındığı ve değerlendirmelerin yapıldığı bölümdür. Bu çalışmanın daha önce yapılan çalışmalardan önemli farkı, doğrusal olmamayı dikkate alarak Diks ve Panchenko nedensellik analizi yapılmasıdır.

\section{KONUNUN NEDEN SEÇiLDiĞí VE OLUŞTURULAN VARSAYIMLAR}

Yazılı ve sözlü medyada, sıklıkla faiz ve enflasyon arasındaki ilişkiye ait siyasilerin söylemleri ile Merkez Bankası Başkanının dolayısı ile kurumun söylemlerine yer verildiği dönemde dikkati çeken nokta, bu iki söylemin birbirinin tam tersi şeylere vurgu yapıyor olmasıydı. Bu makalede, analiz döneminde bu ifadelerden hangisinin gerçeği daha çok yansıttığına cevap bulmak amaçlanmıştır.
İlk olarak bu konuya açıklık getirmek amacı ile hem siyasi söylemlerden hem de kurumsal söylemlerden birkaç örnek vermek uygun olacaktır. Çünkü çalışmanın hipotezleri, bu söylemlere dayanarak belirlenmiştir.

Faiz oranı-enflasyon oranı ve döviz kuru-enflasyon oranı ilişkisi ile ilgili siyasilerin söylemleri arasında en dikkati çekenler, Cumhurbaşkanı Sayın R.T. Erdoğan tarafından yapılanlar olmuştur: I. "Ben enflasyon olayında enflasyon ile faizin ters orantılı değil, doğru orantılı olduğuna inanırım. Yani enflasyon ile faiz arasındaki ilişki sebep-netice ilişkisidir. Faiz sebeptir, enflasyon neticedir. Faizi yükseltirseniz, enflasyon da yükselir. Düşürürseniz, ikisi beraber düşer" (29.01.2014). II. "Yüksek faizi, yüksek enflasyonun sebebi olarak görüyorum. Benim bu noktadaki anlayışım bu. Yani faiz-enflasyon ilişkisinde faiz sebeptir, enflasyon ise neticedir. Ve bunlar doğru orantılıdır... Sizin faiz politikanız yanlış. Olayı kura bağlamak bana göre çok daha yanlış" (25.05.2014). Bu ve benzeri söylemlere farklı tarihlerde yapılan konuşmalarda da rastlanmıştır. ${ }^{1}$

Merkez Bankasının enflasyonla mücadelesinde faiz güçlü bir para politikası aracıdır. MB, "faizleri arttırırsak enflasyon düşer, azaltırsak enflasyon yükselir" şeklinde bir tezden hareket etmektedir. Faiz oranı ve enflasyon oranı ilişkisi ile ilgili Merkez Bankası Başkanı ve Kurum Yetkililerinin söylemleri arasında en dikkati çekenler: I. MB 2014/3729 sayılı Para Politikası Kurulu (PPK) toplantısı sonucunda, "faizlerin düşmesi için öncelikle enflasyonun düşmesi ve hükümetin yapısal reformları hayata geçirmesi gerektiği" mesajı verilmiştir. II. Başçı Cumhurbaşkanı'nın faiz indirime talebine de "Enflasyonu görelim ondan sonra adım atalım" şeklinde cevap verdi (27 Ocak 2015). Bu ifadeler de enflasyonun neden (sebep), faizin ise sonuç (netice) olduğunu ima etmektedir.

Döviz kuru-enflasyon ilişkisi arasında genel kabul gören yaklaşım, döviz kurundaki artışın, enflasyonda yükselme eğilimine yol açacağıdır (döviz kuru sebep, enflasyon sonuç). ${ }^{2}$ Enflasyonla döviz kuru arasındaki ilişkiye bakıldığında, genel olarak döviz kurlarında meydana gelen bir değişiklik fiyatlara yansımaktadır. Özellikle hammadde ve enerji ithalatı yüksek olan ülkelerde, döviz kurundaki yükseliş ithal mal fiyatlarını etkileyerek, fiyatlar genel düzeyinin yükselmesine sebep olur ve bu yükseliş, döviz kurunun enflasyona geçirgenliği olarak isimlendirilir. Döviz kuru-enflasyon oranı ilişkisi ile ilgili Merkez Bankası Başkanı ve Kurum Yetkililerinin 2015 yılı söylemleri arasında en dikkati çekenler şöyle özetlenebilir: I. "Kur oynaklığının enf- 
lasyona etkisi var ama eskisi kadar yüksek değil. Yılsonu enflasyonuna döviz kurunun etkisi 1 puan olacak. Gereken tedbirleri gereken zamanda alırız. Oynaklık geçicidir, orta uzun vadede kredilere ve sermaye akımlarına bakıyoruz. Geçen sene çok sert politika tepkisi verdik şu anda öyle durumda değiliz. Döviz kuru oynaklığı zaman alabilir. Rahat olmak gerekiyor, döviz kuru hareketleri olabilir. Kalıcı hasar bırakmıyor bunlar." II. Başçı doğrudan doğruya döviz kuruna tepki vermenin doğru olmadığını belirterek "Dolaylı adım attığımızda oynaklığın enflasyona etkisi kalıcı olmaz. TL aşırı değerli diyemeyiz" demiştir. Başçı "Döviz satış ihaleleri günlük oynaklığı etkiliyor. TL'deki aşırı zayıflama enflasyon beklentilerini etkilerse ona karşı ılımlı bir politika tepkisi vermek gerekebilir" şeklinde konuşmuştur. Sonuç olarak MB, dönem dönem faiz aracını döviz kurunun artışını engellemek için de kullanmaktadır. Bunun dayanağı da, yukarıda da değinildiği gibi Türkiye'nin özellikle cari açık veren ülke olarak enflasyona kur geçirgenliğinin yüksek olmasıdır. İlgili literatürde yapılan çalışmalar sonucunda, zayıf formda etkin piyasa hipotezinin Türkiye için geçerli olduğuna dair elde edilen yaygın bulgular politika yapıcılarının, önemli bir politika değişkeni olan, döviz kurları piyasası üzerinde bir etkiye sahip olamayacağını göstermektedir. Ayrıca, Türkiye için yapılmış birçok çalışmada satın alma gücü paritesi yaklaşımının geçersiz olması nedeniyle, Türkiye'de reel döviz kurları üzerinde yapılan geçici şokların kalıcı etkileri olabileceği için reel döviz kurlarının uzun dönem değerleri sıkı para politikası ve genişlemeci para politikası uygulamalarından kalıcı bir şekilde etkilenebilir. (Gözen vd., 2016; 139-140).

Siyasilerin, enflasyonun faiz ile doğru orantılı olduğunu, yani enflasyon ile faiz arasındaki ilişkinin neden-sonuç ilişkisi olduğunu (faizin neden, enflasyon sonuç/netice) ifade etmelerine dayanarak yüksek enflasyonun "olağan şüphelisinin" yüksek faiz olduğu noktasından hareketle çalışmanın ilk hipotezi: "faiz, enflasyonun nedenidir" şeklinde oluşturulmuştur. M.B. Eski Başkanının “Enflasyon düşünce faiz indirilebilir. Faiz sonuçtur; sebepleri ise enflasyon, ekonomik ve siyasi istikrar(sızlık)" ifadesine dayanarak çalışmanın ikinci hipotezi: "enflasyon, faizin nedenidir"(MB) şeklindedir. Döviz kuru ile ilgili söylemlerden hareketle oluşturulan üçüncü hipotez ise "döviz kuru, enflasyonun nedenidir" (MB); "döviz kurunu, enflasyonun nedeni olarak kabul etmek doğru değildir" şeklinde oluşturulmuştur. ${ }^{3}$ Hipotezlerden de anlaşılacağı gibi, çalışmanın amacına ulaşmak için kullanılacak uygun yaklaşım, nedensellik analizidir.

\section{YAZIN TARAMASI}

Faiz oranı ve enflasyon ilişkisinin teorik temelleri Fisher'a (1930) kadar uzanmakta olup bu değişkenler arasındaki ilişkiyi analiz eden çalışmalar tarandığında çok sayıda Fisher Etkisinin geçerliliğinin çeşitli yöntem ve yaklaşımlardan yararlanılarak sınandığı uygulamalı çalışmanın var olduğu görülmektedir. Bu çalışmanın amacı, Fisher etkisinin varlığı veya yokluğunu araştırmak olmadığından anılan etki ile ilgili teorik bilgi verilmemiş, ancak yazın taraması bunlar üzerine yoğunlaştığı için bazı örneklere yer verilmiştir. Bunun dışında gelişmiş ve gelişmekte olan ülkelerde, enflasyon ve faiz oranı ilişkisi üzerine yapılan çalışmalarda zaman serileri analiz yöntemlerinin yaygın kullanıldığı, büyük çoğunluğunun doğrusallık varsayımı altında birim kök testleri, eştümleşme, Johansen eştümleşme, VEC modeli, ADL model, VAR modelleri ile ilgili olduğu görülmektedir. Johansen eştümleşme testi ve hata düzeltme modeli ile Fisher etkisinin varlığına ve değişkenler arasında uzun dönem ilişkisi olduğuna karar veren çalışmalara Booth ve Ciner (2001), Yamak ve Abdioğlu (2007), Awomuse ve Alimi (2012), Atgür ve Altay (2015); ARDL yaklaşımı ile etkinin varlığına karar veren Şimşek ve Kadılar (2006); Engle ve Granger ile Parçalı eştümleşme testi ile Fisher etkinin var olduğuna karar veren Turgutlu (2004), sınır testi ile Mercan (2013) örnek olarak verilebilir. Bunlardan farklı olarak Asgharpur vd. (2007), kırk müslüman ülkede uzun dönemde faiz oranı ve enflasyon ilişkisini araştırdığı çalışmada panel veri analizi yöntemi kullanılmış olup, 2002-2005 dönemi için tüm ülkelerde faiz oranı değişkeninden enflasyon oranı değişkenine doğru tek yönlü bir nedensellik ilişkisinin varlığına işaret etmiştir. Doğrusal nedensellik analizinin yapıldığı çalışmalara ise Gül ve Ekinci (2006), Yamak ve Tanrıöver (2007), Akıncı ve Yılmaz (2016) ve Doğan, Eroğlu ve Değer (2016) örnek verilebilir. Gül ve Ekinci (2006), Yamak ve Tanrı̈ver (2007) ile Akıncı ve Yılmaz (2016), Granger nedensellik analizi sonucunda faiz oranından enflasyona tek yönlü nedenselliğin var olduğu bulgusuna ulaşırken Doğan, Eroğlu ve Değer (2016), enflasyondan faiz oranına doğru bir nedensellik ilişkisi bulgusuna ulaşmışlardır.

Daha az sayıda çalışmada enflasyon-faiz oranı ilişkisinin, doğrusal olmaması ile ilgilenilmiştir. Ancak doğrusal olmamayı dikkate alan çalışmalarda genel olarak modelleme yapıldığı veya doğrusal olmayan eştümleşme üzerine yoğunlaşıldığı görülmektedir. Faiz oranı ve enflasyon arasında doğrusal olmayan ilişkiye atıf yapan çalışmalara Weidmann(1997), Million(2004), Maki (2005), Koutas ve Lamarche (2006), 
Lanne(2006), Chiristopoulos ve Leon-Ledesma(2007), Bayat (2012) ve Teker, Aykaç Alp ve Kent (2012) örnek verilebilir. Bunlardan Lanne(2006), doğrusal olmayan birim kök testi ve eştümleşme analizi yaparken Million(2004)-STAR; Chiristopoulos ve Leon-Ledesma(2007)-LSTR; Koutas ve Lamarche (2006)-SETAR; eşik eştümleşme yapanlar ise Weidmann(1997); Bayat(2012) ile Teker, Aykaç Alp ve Kent (2012) TAR birim kök testi ve T-VEC modeli olacak şekilde doğrusal olmayan modeller üzerine yoğunlaşıımışlardır.

Yukarıda da görüldüğü üzere, genel olarak temel alınan değişkenlere ait analizler doğrusalık varsayımı ile yapılmıştır, ancak faiz oranı ve enflasyon oranı gibi değişkenler, çeşitli nedenlerle doğrusal olmayan davranış sergilerler. Örneğin Christopoulos ve LeonLedesma(2007), enflasyon hedeflemesi ve merkez bankalarının deflasyon yaklaşımını (oportunistik davranışı) doğrusal olmamanın bir nedeni / kaynağı olarak gösterirler. Yazında bu konu kapsamında doğrusal olmayan nedensellik ile ilgili çalışmaya rastlanmamıştır.

Döviz kuru enflasyon ilişkisini analiz eden çalışmalar tarandığında da büyük bir kısmının eştümleşme, VAR gibi doğrusallık varsayımı ile yapılan analizler üzerine yoğunlaştığı görülmektedir. Eştümleşme analizi yapan birçok çalışmada Granger nedenselliği ikinci analiz olarak sıkça yer almaktadır. Bunlara sadece eştümleşme analizi yapan ve aralarında uzun dönem ilişkisi olduğu bulgusuna ulaşan Işık, Acar ve Işık (2004) ile VAR analizi yapan Leigh ve Rossi (2002), Peker ve Görmüş (2008) ve Ergin (2015) örnek verilebilir. Bulguları, döviz kurundaki değişmelerin enflasyona etkisinin olduğu şeklinde özetlenebilir. Çok sayıda doğrusal nedensellik analizi yapan çalışma söz konusudur. Bu çalışmaların analiz dönemleri, frekansları farklı olduğu gibi bulguları da farklılıklar göstermektedir. Çeşitli dönemler ve farklı ülkeler için yapılan Granger nedenselliği analizleri sonucunda çift yönlü nedensellik bulgusuna ulaşanlara Koldhy ve Sohrabian (1990) (Almanya ve Japonya için), Altınay (1996), Nourzad (1997), Tarı (1997), Siregar (1999) (alt dönemler için), Maswana (2006) ve Güven ve Uysal(2013); döviz kurundan enflasyona tek yönlü nedensellik bulgusuna ulaşanlara Kholdy ve Sohrabian (1990) (Kanada için), Manning ve Andrianacos (1993), Fisunoğlu ve Çabuk (1998), Koch, Rosensweig ve Witt (1998), Mihaljek ve Klau (2001), Koç ve Abasız (2002), Telatar ve Telatar (2003), Gül ve Ekinci(2006) ve Yanar (2008); enflasyondan (fiyat değişmeleri) döviz kuruna tek yönlü nedensellik bulgusuna ulaşanlara ise Man- ning ve Andrianacos (1993), Rittenberg (1993), Rahman, Mustafa ve Bailey (1996), Terzi ve Zengin(1996), Kim (1998), Siregar (1999) (tüm dönem için) örnek olarak verilebilir. Agayev(2011) ise Azerbaycan için yaptığı analizler sonrasında bu iki değişken arasında eştümleşmenin ve nedenselliğin olmadığı bulgusuna ulaşmıştır. Yapılan yazın taramasında enflasyon ile döviz kuru arasında doğrusal olmayan nedensellik analizinin yapıldığı bir çalışmaya rastlanmamıştır.

\section{UYGULAMA}

$\mathrm{Bu}$ bölümde analiz edilecek veriler tanıtılarak durağanlık ve doğrusalık testleri yapılmakta, testler ve yöntemler hakkında kısa bilgiler verilmekte ve nedensellik analizleri yapılarak bulgular değerlendirilmektedir.

\subsection{Veri Seti ve Verilerin Analizi}

Analiz dönemi, 2003 güçlü ekonomiye geçiş programı ile başlayan ve 2016 Mart sonuna kadar olan zaman dönemini (2003:01-2016:03) kapsamaktadır. Analiz edilecek değişkenler ise TÜFE, ÜFE ve Özel kapsamlı TÜFE enflasyonu [ENF(tüfe), ENF(üfe) ve ENF(ötüfe)], Amerikan Doları (DK) ve BIST Bankalararası Para Piyasasındaki Gecelik Repo Faiz Oranıdır(FAIZ). Tüm değişkenlerin zaman serisi grafiklerinde varyansda durağan olmama görülmüş ve tümüne logaritmik dönüşüm yapılmıştır. Döviz kuru olarak Amerikan Doları satış fiyatı alınmış ve logaritmik dönüşüm ile LDK serisi elde edilmiştir. Döviz kuru için analizler tüm dönemin yanı sıra yapısal kırılma analizi sonucu 2008:10'un kırılma dönemi olduğu belirlenmiş ve bu tarihe karşı gelen ve tüm dünyayı etkileyen finansal krizin, nedensellik ilişkisinin yönünü ve etkisini değiştirip değiştirmediğini görebilmek için 2003:012008:10 (kırılma öncesi) ve 2008:11-2016:03 (kırılma sonrası) olmak üzere iki alt dönem için de yapılmıştır. Faiz oranı serisi olarak BIST Bankalararası Para Piyasasındaki Gecelik Repo Faiz Oranı alınmış, logaritmik dönüşüm ile LFAIZ serisi elde edilmiştir. BIST Repo piyasaları, TCMB'nin politika faizi, likidite yönetimi ve diğer politika araçlarının etkilediği en derin para piyasası olması sebebiyle önem arz etmekte olup Türkiye'de kısa vadeli piyasa faizlerini en iyi temsil eden piyasalardan biri olarak kabul edilmektedir. Faiz oranı için yapılan kırılma analizleri sonucu 2011:10'un kırılma dönemi olduğu belirlenmiş ve analizler tüm dönemin yanı sıra 2003:01-2011:10(kırılma öncesi) ve 2011:11-2016:03(kırılma sonrası) alt dönemleri için de yapılmıştır. Enflasyon oranları olarak TÜFE, ÜFE ve Özel kapsamlı TÜFE (enerji hariç) enflasyonu olmak 
üzere üç enflasyon hesaplanmış ve analizler üçü içinde yapılmıştır. L, logaritmik dönüşümü göstermek üzere örneğin Tüfe enflasyonu Enf(tüfe $)_{t}=$ LTUFE $_{t}-L-$ TUFE $_{\mathrm{t}-1}$ olarak hesaplanmıştır. ÖTUFE, özel kapsamlı TÜFE göstergeleri: ÖKTG, TÜFE'den bazı alt kalemlerin çıkarılması yoluyla ulaşılan endeksdir, başka bir deyişle gıda ve enerji gibi fiyatları oynak malları dışarıda bırakan enflasyon ölçümüdür. Bir anlamda çekirdek enflasyon, kısa vadeli arz ve talep koşullarından daha az etkilendiği ve merkez bankalarının para politikaları yoluyla kontrol edebileceği fiyatları gösterdiği için bazı ekonomistler tarafından gerçek enflasyon olarak değerlendirilir.

\subsection{Ekonometrik Yöntemler}

Bu bölümde ilk olarak Dickey ve Fuller(1979): DF(1979), Enders ve Granger(1998): EG, Kapetanios, Shin ve Snell(2003): KSS ve Sollis(2004): Sollis04 durağanlık/birim kök testleri ile Brock, Dechert ve Scheinkman(1987): BDS doğrusallık testinden kısaca bahsedilerek uygulama yapılmakta, ardından bulgulardan hareketle Dicks ve Panchenko doğrusal olmayan nedensellik testi uygulanmaktadır.

\subsubsection{Birim kök testleri}

\section{DF(1979) Testi}

Dickey ve Fuller(1979) testi, doğrusal olan serilerin birim köke sahip olup olmadığını belirlemede kullanılan bir test olup seride kırılma veya yapısal değişme olması, serilerin doğrusal olmaması ve/ veya asimetrinin olması durumunda testin gücünün ve sonuçlarının güvenilirliğin azaldığı bilinmektedir. DF testinin doğrusal olmama/asimetrik ayarlamalar için uygun olmadığı çeşitli çalışmalarla gösterilmiştir. Bunlardan biri de Enders ve Granger (1998) çalışmasıdır. Bu makalede DF dışında kullanılan diğer testler, EG, KSS ve Sollis04 testleri, doğrusal olmayan serilerin durağan olup olmadığını belirlemede kullanılan, doğrusal olmama ve asimetrik ayarlama özelliklerini ortaya çıkarmada yararlı olan, birim kök durağan olmama ile doğrusal olmayan ama durağan serileri ayırt eden testlerdir.

\section{EG Testi}

Enders ve Granger(1998), alternatif hipotez altında asimetrik ayarlamaya izin veren bir yeni birim kök testi geliştirmiş ve asimetrik ayarlamaların dinamiklerini belirlemek için, eşik doğrusal olmayan modelleri kullanmışlardır. Eşik otoregresif (threshold autoregressive): TAR ve M-TAR (momentum TAR) model yapısında geliştirilen birim kök testinin alternatif hipotezi, sabit ortalamaya veya deterministik doğrusal trende doğru durağan asimetrik ayarlama olarak ifade edilir. Test istatistikleri üç aşamalı bir süreçle hesaplanır: a)zaman serisinin deterministik bir trende sahip olup olmadığını belirlemek amacıyla görsel olarak incelenmesi. b) zaman serisi $y_{t}^{\prime}$ nin ilgili deterministik kısım üzerine EKK yöntemiyle regresyonun yapılması ve bu regresyondan elde edilen artıkların, $\hat{v}_{t}$, kaydedilmesi ve ardından TAR modelinden yararlanarak test denklemlerinin oluşturulması: ilk olarak $\Delta \hat{v}_{t}=I_{t} \rho_{1} \hat{v}_{t-1}+\left(1-I_{t}\right) \rho_{2} \hat{v}_{t-1}+\eta_{t}$ test denklemi oluşturulurken artıklarda otokorelasyon olması durumunda $\Delta \hat{v}_{t}=I_{t} \rho_{1} \hat{v}_{t-1}+\left(1-I_{t}\right) \rho_{2} \hat{v}_{t-1}+\sum_{i=1}^{k} \phi_{i} \Delta \hat{v}_{t-i}+\eta_{t}$ test denklemi oluşturulur. Burada $\hat{v}_{t-1} \geq 0$ ise $I_{t}=1 ; \quad \hat{v}_{t-1}<0$ ise $I_{t}=0$ değerlerini almaktadır. k değeri, $\eta_{t}$ 'nin saf hata terimi (white noise) olmasını sağlayacak uzunlukta seçilir. Test hipotezleri $H o: \rho_{1}=\rho_{2}=0$ hipotezi (birim kök süreci) için $F$ -istatistiği veya $H o: \rho_{1}=0$ veya $H o: \rho_{2}=0$ hipotezleri için en anlamlı $t$-istatistiği $(t-\max )$ olacak şekilde oluşturulur. c) artıklar $\eta_{t}$ için kontrol amaçlı testlerin uygulanması. Testin kritik değerleri, Monte Carlo benzeşimi kullanarak hesaplanmıştır.

\section{KSS testi}

Kapetanios, Shin ve Snell( 2003), durağan olmayan doğrusal süreci durağan ancak doğrusal olmayan süreçten ayırmayı sağlayacak bir yaklaşım önermiştir. KSS, $\Delta y_{t}=\gamma y_{t-1}\left[1-\exp \left(-\theta y_{t-1}^{2}\right)\right]+\varepsilon_{t} \quad(\theta \geq 0)$ şeklinde ESTAR tanımlamasından yararlanır. $y_{t}$ trendden arındırılmış zaman serisi, $\gamma$ bilinmeyen parametre ve $\varepsilon_{t}, \varepsilon_{t} \sim$ i.i.d. $\left(0, \sigma^{2}\right)$ dir. Teste doğrusal olmayan ayarlama için $\left[1-\exp \left(-\theta y_{t-1}^{2}\right)\right]$ üstsel geçiş fonksiyonu (exponential transition function) uyarlanmıştır. Test hipotezleri $H_{0}: \theta=0$ ve $H_{a}: \theta>0$ olarak ifade edilir. $H_{0}$ hipotezi altında yt, doğrusal birim kök süreci izlerken Ha hipotez altında bir doğrusal olmayan durağan ESTAR süreci izler. $H_{0}$ direk test edilemeyeceği için $\Delta y_{t}=\delta y_{t-1}^{3}+\varepsilon_{t}$ yardımcı regresyon denklemi elde edilir. Serisel korelasyon varsa denklem $\Delta y_{t}=\sum_{j=1}^{p} \rho_{j} \Delta y_{t-j}+\delta y_{t-1}^{3}+\varepsilon_{t}$ genişletilir. Test hipotezleri $H_{0}: \delta=0$ ve $H_{a}: \delta<0$, test istatistiği $t_{N L}=\frac{\delta}{\text { s.e. }(\hat{\delta})}$ dir. $H_{0}$ hipotezi, bir doğrusal sürecini; $H_{a}$ hipotezi bir doğrusal olmayan ama global olarak durağan süreci göstermektedir. $t_{N L}$, asimptotik standart normal dağılıma sahip değildir, asimptotik kritik değerler benzeşimlerle elde edilir. 


\section{Sollis04 Testi}

Sollis(2004) birim kök testi, Enders ve Granger(1998):EG ve Leybourne, Newbold ve Vougas(1998):LNV testlerindeki benzerlikten hareket ederek, her ikisinde de deterministik kısımların birim kök testinden önce ayrıştırılması işlemi nedeniyle, bir arada kullanılabileceğini belirterek tasarlanmıştır. Sollis04 birim kök testinde, EG testi, doğrusal olmayan bir çekiciyi içerecek şekilde genişletilmiş ve etrafında durağan asimetrik ayarlama oluşabilen deterministik doğrusal trendler arasında yumuşak geçiş içeren bir alternatif hipotezi içerecek şekilde LNV testi ile birleştirilmiş ve TAR yerine yumuşak geçişli TAR:ST-TAR modeli temel alınmıştır. Testin hareket noktası LNV'nin Model $A, B, C$ diye adlandırılan üç lojistik yumuşak geçişli regresyon: STR modelleridir:

$$
\begin{gathered}
\text { Model A: } y_{t}=\alpha_{1}+\alpha_{2} S_{t}(\gamma, \tau)+v_{t} \\
\text { Model B: } y_{t}=\alpha_{1}+\beta_{1} t+\alpha_{2} S_{t}(\gamma, \tau)+v_{t} \\
\text { Model C: }=\alpha_{1}+\beta_{1} t+\alpha_{2} S_{t}(\gamma, \tau)+\beta_{2} t S_{t}(\gamma, \tau) \dashv \\
v_{t} \sim \text { i.i.d. }\left(0, \sigma^{2}\right) \quad \text { ve } \quad S_{t}\left(\gamma_{t}, \tau\right), \\
S_{t}\left(\gamma_{t}, \tau\right)=[1+\exp \{-\gamma(t-\tau T)\}]^{-1}, \gamma>0 \quad \text { olacak }
\end{gathered}
$$
şekilde tanımlanan $T$ örnek büyüklüğüne dayanan lojistik yumuşak geçiş fonksiyonudur. Bu modellere ait denklemlerden artıklar, $\hat{v}_{t}$, elde edilir ve $\hat{v}_{t}$ için aşağıdaki TAR tipi test denklemi oluşturulur. $\Delta \hat{v}_{t}=I_{t} \rho_{1} \hat{v}_{t-1}+\left(1-I_{t}\right) \rho_{2} \hat{v}_{t-1}+\sum_{i=1}^{k} \phi_{i} \Delta \hat{v}_{t-i}+\eta_{t}$ . Burada $v_{t-1}>0$ için $I_{t}=1$ ve $v_{t-1} \leq 0$ için $I_{t}=0$ değerlerini alan bir gösterge fonksiyonu, $\eta_{t}$ sıfır ortalamalı durağan süreçtir. Test hipotezleri ve test istatistikleri $\mathrm{F}$ ve $\mathrm{t}$-istatistikleridir. Test kritik değerleri Monte Carlo benzeşimleri ile hesaplanmıştır. $y_{t}$ 'nin deterministik kısmının belirlenmesinde, hangi model olacağı önemli değildir, $\rho_{1}=\rho_{2}=0$ olduğunda $v_{t}$ dolayısı ile $y_{t}$ bir birim köke sahip olur. $\rho_{1}=\rho_{2}<0$ olması durumunda $y_{t}$ simetrik uyarlamalı bir durağan ST-TAR süreci, veya $\rho_{1}<0, \rho_{2}<0$ ve $\rho_{1} \neq \rho_{2}$ olması durumunda $y_{t}$, asimetrik uyarlamalı bir durağan ST-TAR sürecidir. $y_{t}$ 'nin bir birim kökü olup olmadığını belirlemek için $\rho_{1}=\rho_{2}=0$ testi için F-istatistiği ve/veya $\rho_{1}=0$ ve $\rho_{2}=0$ testinden elde edilen $\mathrm{t}$-istatistiklerinin en anlamlısı (t-max) kullanılır. Model A için $\mathrm{F}$ ve $\mathrm{t}$ istatistikleri $F_{\alpha}, t s_{\alpha}$; Model B için $F_{\alpha(\beta)}, t s_{\alpha(\beta)}$ ve Model C için $F_{\alpha \beta}$, $t s_{\alpha \beta}$ olarak isimlendirilir.

4.2.2. BDS Doğrusallık testi (Doğrusal Olmayan Bağımlılık Testi)

Nedensellik analizine başlamadan önce, durağan oldukları belirlenen serilerin doğrusal olup olmadı- ğının belirlenmesi gerekmektedir. Bulgulara göre, doğrusal Granger nedensellik testi veya doğrusal olmayan Granger nedensellik testi uygulanacaktır. Bu nedenle serilerde doğrusal olmamanın varlığının doğrulanması, büyük önem taşımaktadır. Brock, Dechert ve Scheinkman (1987) tarafından tanıtılan, daha sonra Brock, Hsieh ve LeBaron (1991) tarafından geliştirilen BDS testi, zaman serisinin cari ve geçmiş değerleri arasındaki otokorelasyonu inceleyen bir doğrusal olmama testidir (Koç ve Beşer (2006)). Korelasyon entegraline bağlı olarak hesaplanır ve parametrik olmayan bir testtir.

BDS test istatistiği $B D S_{\varepsilon, m}=\frac{\sqrt{N}\left[C_{\varepsilon, m}-\left(C_{\varepsilon, 1}\right)^{m}\right]}{\sqrt{V_{\varepsilon, m}}}$ formülü ile hesaplanır. Çift taraflı bir test olup test istatistiğinin kritik değerden ( $\alpha=0.05$ için ktirik değer $= \pm 1.96$ ) büyük veya küçük olması durumunda $H_{0}$ sıfır hipotezi rededilir. Burada korelasyon integrali $C_{\varepsilon, m}, \varepsilon$ Euclid uzakIığı, $I_{i, j ; \varepsilon}, I_{i, j ; \varepsilon}=\left\{\begin{array}{ll}=1 & \left\|x_{i}^{m}-x_{j}^{m}\right\| \leq \varepsilon \text { için } \\ =0 & \text { diğer hallerde }\end{array}\right.$, bir gösterge fonksiyonu olmak üzere $C_{\varepsilon, m}=\frac{1}{N_{m}\left(N_{m}-1\right)} \sum_{i \neq j} I_{i, j, \varepsilon}$ dir. Varyans $V_{\varepsilon, m^{\prime}}$ $C_{\varepsilon, m}=\frac{1}{N_{m}\left(N_{m}-1\right)} \sum_{i \neq j} I_{i, j, ; ;} \quad h_{i, j, N ; \varepsilon}=\frac{\left[I_{i, j ; z} I_{j, N ; \varepsilon}+I_{i, N ; \varepsilon} I_{N, j ; \varepsilon}+I_{j, i, \varepsilon} I_{i, N ; \varepsilon}\right]}{3}$ için $V_{\varepsilon, m}=4\left[K^{m}+2 \sum_{j=1}^{m-1} K^{m-j} C_{\varepsilon}^{2 j}+(m-1)^{2} C_{\varepsilon}^{2 m}-m^{2} K C_{\varepsilon}^{2 m-2}\right]$ dir. BDS testi, zaman serilerinde doğrusal olmayan serisel bağımlılığı ortaya çıkaran bir testtir. Zaman serilerinden doğrusal yapıyı ortadan kaldırmak için uygun bir doğrusal model uydurarak trendden arındırma veya ilk farkının alınmasının ardından uygulanır. Arta kalan kalıntıların iid olduğunu ifade eden $H_{0}$ hipotezinin red edilmesi, zaman serisinin arta kalan yapısının bir saklı doğrusal olmamayı içermesi ile aynı anlama gelir.

$\mathrm{Bu}$ makalede doğrusallığın sınanması BDS testi ile yapılmış, tüm analiz dönemi ile kırılma öncesi ve kırılma sonrası dönem için ayrı ayrı BDS testi uygulanmıştır. Test sonucu tüm serilerin doğrusal olmadıkları belirlenmiştir.

\subsubsection{Diks ve Panchenko Doğrusal olmayan nedensellik testi}

Durağan ancak doğrusal olmadıkları belirlenen seriler için doğrusal olmayan nedensellik testi uygun olacağı için bu çalışmada Diks ve Panchenko (Diks ve Panchenko, 2006) testi uygulanmıştır. Doğrusallığın olmaması durumunda standart Granger nedensellik test yaklaşımı, seriler arasındaki doğrusal olmayan nedensellik ilişkisinin varlığını ortaya çıkarmak için uygun değildir. Çünkü doğrusal Granger nedensellik analizi değişkenler arasındaki doğrusal olmayan nedensel ilişkileri dikkate almaz. Bu konu ile ilgili 
olarak Baek ve Brock(1992), Monte Carlo denemeleri ile doğrusal olmamanın varlığı durumunda doğrusal olmama yaklaşımlarının öngörü başarılarının doğrusal modellerden daha başarılı olduğunu ortaya koymuşlardır. Baek ve Brock (1992), bu testin gücünün, bir doğrusal yapı içinde oluşturulduğunda bir doğrusal olmama alternatifine karşı daha düşük olduğuna işaret etmişlerdir. Bu kapsamda yeni bir test tanıtmışladır. Ancak parametrik olmayan Baek ve Brock(1992) testi, katı varsayımları nedeni ile yaygın uygulanmamıştır. Doğrusal olmayan Granger nedenselliğinin yokluğunu ifade eden $H_{0}$ hipotezi, ilk olarak Hiemstra ve Jones (1994), daha sonra da Diks ve Panchenko(2006):DP(2006) tarafından tanitılan parametrik olmayan bir test ile sınanmıştır. DP(2006), Hiemstra ve Jones(1994) testinin bir sapma nedeni ile tutarsız olduğunu ve test istatistiğinde küçük band genişliği seçimi ile ortadan kaldırılamayacağını iddia ederek yeni bir test tanıtmışlardır, bu test $H_{0}$ hipotezinin sıklıkla reddedilmesi riskini ve sapmayı azaltan bir testtir. HJ testi, örnek hacmi arttığında $H_{0}$ hipotezini daha sıklıkla reddeder. DP tarafından geliştirilen doğrusal olmayan nedensellik testi, bu sakıncanın üstesinden gelmiştir. Doğrusal olmayan nedenselliğin varlığı da iki değişken arasındaki dinamik ilişkinin doğrusal olmadığı şeklinde yorumlanabilir.

Diks ve Panchenko (2006) nedensellik testi, parametrik olmayan doğrusal olmayan nedensellik testi olup doğrusal olmayan nedenselliği test etmek için, ilk olarak doğrusal bağımlıı̆ı̆ ortadan kaldırılması gereklidir. Diks ve Panchenko (2006) doğrusal olmayan nedensellik analizinde doğrusal bağımlılığı (linear dependence) ortadan kaldırmak için önce VAR modelinin tahmin edilmesini ve doğrusal olmayan nedensellik analizinin VAR modelinin artıklarına uygulanmasını önermişlerdir. Böylece VAR filtrelenmiş artıkları, orijinal verinin doğrusal olmayan yapısını çıkarmak için kullanıır.
Test istatistiği, birleşik olasılık yoğunluk fonksiyonlarını göstermek üzere $T_{n}\left(\varepsilon_{n}\right)=\frac{n-1}{n(n-2)} \sum_{i}\left(\hat{f}_{X, Z, Y}(X i, Z i, Y i) \hat{f}_{Y}(Y i)-\hat{f}_{X, Y}(X i, Y i) \hat{f}_{Y, Z}(Y i, Z i)\right)$ dir. Diks-Panchenko, $\varepsilon_{n}=\mathrm{Cn}^{-\beta} \quad C>0, \frac{1}{4}<\beta<\frac{1}{3}$ için $\sqrt{n} \frac{\left(T_{n}\left(\varepsilon_{n}\right)-q\right)}{S_{n}} \stackrel{D}{\longrightarrow} N(0,1)$ test istatistiğinin dağılımda Normale yakınsadığını göstermiştir. D dağılımda yakınsamayı göstermekte olup $S_{n}$, asimptotik varyans $T_{n}($.$) 'nin$ tahmincisidir. Filtreleme süreci, doğrusal VAR modelinin doğru seçilmesine dayandığı için VAR modeli tanımlamasında artıkların iid Normal dağılması ile ilgili varsayımın, $\varepsilon_{t} \sim N$.i.i.d. $\left(0, \sigma^{2}\right)$ sağlanması noktasında dikkatli olunmalıdır.

$\mathrm{Bu}$ makalenin uygulama kısmında değişkenler arasındaki nedensellik ilişkisinin varlığını veya yokluğunu ortaya koymak için VAR modeli, $Y_{t}=\{$ Enf, Faiz $\}$ ve $Y_{t}=\{E n f, D K\}$ olacak şekilde $Y_{t}=\sum_{i=1}^{k} A_{i} Y_{t-i}+\varepsilon_{t}$ oluşturulmuş ve artıklarına parametrik olmayan Diks ve Panchenko (2006) testi uygulanmıştır.

\subsection{Bulgular ve Değerlendirme}

Serilerin durağanlığının test edilmesinde kullanılan test istatistiklerinin 2003-2016 dönemi için sonuçları Tablo 1' de verilmiştir. Diğer alt dönemlerde de yapılan testlerle durağanlıkların sağlandığı görülmüştür.

Durağanlık testlerinin sonuçlarına göre, LFAIZ ve LDK serilerinde (tüm testlerde) birim kökün varlığını ifade eden $H_{0}$ hipotezinin red edilmemiş olduğu görülmektedir. Bunun üzerine farkı alınan serilere (DLFAIZ ve DLDK) aynı testler uygulanmış ve bu seriler için $H_{0}$ hipotezi reddedilmiştir. Bu da fark serilerinin durağan olduğunu göstermektedir. ENF(tüfe), ENF(üfe) ve ENF(otüfe) değişkenleri için EG-F ve KSS testleri sonucunda $\% 5$ düzeyinde durağan oldukları, ancak Sollis04 testine göre ENF(tüfe), ENF(üfe) değişkenleri \%5 düzeyinde durağan iken ENF(ötüfe) değişkeninin $\% 10$ düzeyinde durağan olduğu belirlenmiştir.

Tablo 1: Seriler için Durağanlık Sınaması Sonuçları (2003:01-2016:03)

\begin{tabular}{|c|c|c|c|c|}
\hline & $\begin{array}{c}\text { ADF } \\
(-2.89) /(-2.56) \\
\end{array}$ & $\begin{array}{c}\text { EG-F } \\
(3.79) /(4.67) \\
\end{array}$ & $\begin{array}{c}\text { KSS } \\
(-2.93) /(-2.66) \\
\end{array}$ & $\begin{array}{c}\text { Sollis 04-t } \\
(-3.417) /(-3.169) \\
\end{array}$ \\
\hline LFAIZ & -1.40 & 2.17 & -2.31 & -2.06 \\
\hline LDK & -1.16 & 3.26 & -1.28 & -1.93 \\
\hline ENF(tüfe) & $-8,31$ & 55.11 & -5.39 & $-3,84$ \\
\hline ENF(üfe) & $-6,12$ & 43.02 & -7.15 & $-3,64$ \\
\hline ENF(otüfe) & $-7,19$ & 31.12 & 7.36 & $-3,13 * *$ \\
\hline DLFAIZ & -6.14 & 9.16 & -8.71 & -6.14 \\
\hline DLDK & -8.12 & 11.08 & -8.47 & -7.81 \\
\hline
\end{tabular}


Ardından durağan serilerin doğrusal olup olmadıkları BDS testi yardımı ile belirlenmiş ve Tablo 'da sadece 3 farklı dönem için de serilerin bağımsız ve özdeş (i.i.d) olduğunu ifade eden sıfır hipotezinin \%5 anlamlılık düzeyinde reddedildiği değerler verilmiştir.

Yukarıda da değinildiği gibi, faiz ve döviz kurundaki kırılmalara bağlı olarak test sonuçlar FAIZ için 2003:01-2011:10 (kırılma öncesi) ve 2011:11-2016:03 (kırılma sonrası); DK için 2003:01-2008:10 (kırılma öncesi) ve 2008:11-2016:03 (kırılma sonrası) olacak şekilde alt dönemler için yapılmış ve aşağıda tablolanmıştır.

$\mathrm{Bu}$ bulgular, serilerde tüm analiz döneminde, kırılma öncesi ve kırılma sonrası dönemlerde doğrusal olmayan yapının varlığını ortaya koymaktadır. Serilerin durağan ancak doğrusal olmadıkları belirlendikten sonra Diks ve Panchenko testi doğrusal olmayan nedensellik testi yapılmıştır. ENF(ötüfe) serisi hariç diğer serilerin kurtosis değerlerinin yüksek olması ${ }^{4}$ (leptokurtik), Diks ve Panchenko (2006) da vurgulandığı üzere, veri setinde değişen varyans yapısının varlığını ima etmekte ve doğrusal olmayan nedensellik testinin kullanılmasını desteklemektedir.
Yukarıda da değinildiği üzere, bu test yaklaşımında ilk olarak doğrusal bağımlıı̆ı ortadan kaldırmak gerekmektedir. Bunun için Diks ve Panchenko (2006) önerdiği gibi, VAR modelleri tahmin edimiş ve doğrusal olmayan nedensellik analizi VAR modelinin artıklarına uygulanmıştır. Böylece, VAR filtrelenmiş artıkları, orijinal verinin doğrusal olmayan yapısını çıkarmak için kullanılmıştır. Uygulamada yapılan filtrelemede, iki değişkenli VAR modelinden yararlanılmıştır. FAIZ ve DK'nun ayrı olarak enflasyonla ilişkilerinin analiz edildiği VAR modellerinde, artıklarında normalliği sağlamak amacı ile çeşitli kukla değişkenler eklenmiştir. Çünkü DP testinin uygulanabilir olması için tahmin edilen VAR modeli artıklarının normal dağılması, sıfır ortalama ve sabit varyansa sahip olması gerekmektedir. Bunun üzerine oluşturulan VAR modellerinin geçerliliği sınanmış ve artıkların normal dağıldığı, sıfır ortalama ve sabit varyansa sahip olduğu (N.i.i.d) görülmüş, bunun üzerine artıklarla Diks ve Panchenko doğrusal olmayan nedensellik testi uygulanmıştır. Tablo 3'te LR test sonuçlarına göre VAR modelleri için uygun gecikme uzunlukları verilmiştir.

Tablo 2: FAiZ, DK, ENF(UFE), ENF(TUFE) VE ENF(OTUFE) için BDS Testi Sonuçları

\begin{tabular}{|c|c|c|c|c|}
\hline \multicolumn{5}{|c|}{ FAIZ-ENFLASYON için 2003:01-2016:03 } \\
\hline & DLFAIZ & ENF(UFE) & ENF(TUFE) & ENF(OTUFE) \\
\hline$\varepsilon / \sigma(* *)$ & 2 & 3 & 2 & 1 \\
\hline 0,5 & 2.89 & 3.14 & 2.97 & 2.65 \\
\hline \multicolumn{5}{|c|}{ 2003:01-2011:10 } \\
\hline & DLFAIZ & ENF(UFE) & ENF(TUFE) & ENF(OTUFE) \\
\hline$\varepsilon / \sigma(* *)$ & 3 & 2 & 3 & 2 \\
\hline 0,5 & 3.01 & 1.99 & 2.13 & 3.14 \\
\hline \multicolumn{5}{|c|}{ 2011:11-2016:03 } \\
\hline$\varepsilon / \sigma(* *)$ & DLFAIZ & ENF(UFE) & ENF(TUFE) & ENF(OTUFE) \\
\hline \multirow[t]{2}{*}{0,5} & 2 & 3 & 3 & 2 \\
\hline & 3.54 & 2.18 & 2.41 & 2.95 \\
\hline \multicolumn{5}{|c|}{ DÖViz KURU - ENF için 2003:01-2016:03 } \\
\hline$\varepsilon / \sigma(* *)$ & DLDK & ENF(UFE) & ENF(TUFE) & ENF(OTUFE) \\
\hline \multirow[t]{3}{*}{0,5} & 1 & 3 & 2 & 1 \\
\hline & 3.05 & 3.14 & 2.97 & 2.65 \\
\hline & \multicolumn{4}{|c|}{ 2003:01-2008:10 } \\
\hline$\varepsilon / \sigma(* *)$ & DLDK & ENF(UFE) & ENF(TUFE) & ENF(OTUFE) \\
\hline \multirow[t]{3}{*}{0,5} & 1 & 2 & 3 & 2 \\
\hline & 2.94 & 2.12 & 2.54 & 3.13 \\
\hline & \multicolumn{4}{|c|}{ 2008:11-2016:03 } \\
\hline$\varepsilon / \sigma(* *)$ & 2 & 3 & 3 & 2 \\
\hline 0,5 & 3.71 & 2.81 & 2.64 & 3.06 \\
\hline
\end{tabular}


Tablo 3: Oluşturulan VAR Modellerinin Gecikme Uzunlukları

\begin{tabular}{|c|c|c|}
\hline Değişkenler & LR & $\begin{array}{c}\text { Gecikme } \\
\text { Uzunluğu }\end{array}$ \\
\hline DLFAIZ - ENF(tüfe) & 45.46 & 2 \\
\hline DLFAIZ - ENF(üfe) & 30.33 & 2 \\
\hline DLFAIZ - ENF(ötüfe) & 32.78 & 1 \\
\hline DLDK - ENF(tüfe) & 29.18 & 2 \\
\hline DLDK - ENF(üfe) & 25.72 & 3 \\
\hline DLDK - ENF(ötüfe) & 27.42 & 3 \\
\hline
\end{tabular}

DP testi, band genişliği $\boldsymbol{\varepsilon}=1,5$ için ve $L x=L y=1,2,3,4,5$ olacak şekilde farklı gecikmeler için uygulanmıştır. VAR modelinin artıklarına uygulanan doğrusal olmayan nedensellik analizi sonuçları, 20032016, 2003-2008/2003-2011 ve 2008-2016/20112016 dönemleri için ayrı ayrı ve sadece istatistiksel anlamlı olan ilişkiler için Tablo 4'de verilmiştir.

Tablo 4: Diks ve Panchenko (2006) Doğrusal Olmayan Nedensellik Testi Sonuçları $\left({ }^{*}\right)$

\begin{tabular}{|c|c|c|c|c|}
\hline$\varepsilon=1.5^{(1)}$ & 2003:01-2016:03 & $\begin{array}{c}\text { Gecikme/t-ist/ } \\
\text { p-değeri }\end{array}$ & 2003:01-2016:03 & $\begin{array}{l}\text { Gecikme/t-ist/ } \\
\text { p-değeri }\end{array}$ \\
\hline & DLFAIZ $\rightarrow$ ENF(üfe) & 2 & DLDK $\rightarrow$ ENF(tüfe) & 2 \\
\hline & & 1.86 & & 3.89 \\
\hline & & $(0.04)^{*}$ & & $(0.01)^{*}$ \\
\hline & ENF(üfe) $\rightarrow$ DLFAIZ & 1 & DLDK $\rightarrow$ ENF(üfe) & 3 \\
\hline & & 2.14 & & 4.02 \\
\hline & & $(0.03)^{*}$ & & $(0.01)$ \\
\hline & 2003:01-2011:10 & 1 & DLDK $\rightarrow$ ENF(ötüfe) & 1 \\
\hline & DLFAIZ $\rightarrow$ ENF(tüfe) & 2.01 & & 3.59 \\
\hline & & $(0.05)^{*}$ & & $(0.01)^{*}$ \\
\hline & DLFAIZ $\rightarrow$ ENF(üfe) & $2 / 3$ & 2003:01-2008:10 & \\
\hline & & $4.13 / 3.64$ & DLDK $\rightarrow$ ENF(ötüfe) & 1 \\
\hline & & $(0.01) /(0.01)$ & & 3.71 \\
\hline & DLFAIZ $\rightarrow$ ENF(ötüfe) & 1 & & $(0.02)^{*}$ \\
\hline & & 3.87 & 2008:11-2016:03 & \\
\hline & & $(0.01)^{*}$ & DLDK $\rightarrow$ ENF(tüfe) & 4 \\
\hline & ENF(üfe) $\rightarrow$ DLFAIZ & 2 & & 4.06 \\
\hline & & 3.02 & & $(0.01)^{*}$ \\
\hline & & $(0.03)^{*}$ & DLDK $\rightarrow$ ENF(üfe) & 3 \\
\hline & ENF(ötüfe) $\rightarrow$ DLFAIZ & 3 & & 4.11 \\
\hline & & 3.05 & & $(0.01)^{*}$ \\
\hline & & $(0.03)^{*}$ & DLDK $\rightarrow$ ENF(ötüfe) & 1 \\
\hline & 2011:10-2016:03 & & & 3.93 \\
\hline & -- & & & $(0.02)^{*}$ \\
\hline
\end{tabular}

(*) Sadece istatistiksel anlamlı olan gecikmeler, t-istatistiği ve $p$-değerleri tablolanmıştır.

(1) $\boldsymbol{\varepsilon}^{\prime}$ nin değerleri, DP tarafından tablolaştırıımış ve $\mathrm{N}=200$ için $\boldsymbol{\varepsilon}=1,5$ olarak verilmiştir (Diks ve Panchenko, 2006: Tablo 1, 1658).

Bu tabloda verilmiş olan değerler, örneğin $H_{0}$ hipotezinin FAIZ-ENF(üfe) \%4 ve ENF(üfe)-FAIZ \%3 anlamlılık düzeyinde, sırası ile 2. ve 1. gecikmelerde reddedilmiş olduğunu göstermektedir.
Tablo 4'de özetlenmiş olan bulgular, dönemler itibari ile ayrıştırılarak nedensellik yönünü de gösterecek şekilde aşağıda özetlenmiştir. 
Tablo 5: Doğrusal Olmayan Nedenselliğin Yönü

\begin{tabular}{|c|c|c|}
\hline $2003: 01-2016: 03$ & 2003:01-2011:10 & $2011: 11-2016: 03$ \\
\hline$F A I Z \rightleftarrows E N F(\ddot{u} f e)$ & $F A I Z \rightarrow E N F(t u ̈ f e) \quad(S Y S)$ & - \\
\hline$(S Y S+M B)$ & $F A I Z \rightleftarrows E N F($ üfe $) \quad(S Y S+M B)$ & \\
\hline & $F A I Z \rightleftarrows E N F($ ötüfe $)(S Y S+M B)$ & \\
\hline $2003: 01-2016: 03$ & $2003: 01-2008: 10$ & $2008: 11-2016: 03$ \\
\hline$D K \rightarrow E N F($ üfe $) \quad(M B)$ & $D K \rightarrow E N F($ ötüfe $) \quad(M B)$ & $D K \rightarrow E N F(\ddot{u} f e) \quad(M B)$ \\
\hline$D K \rightarrow E N F($ tüfe $) \quad(M B)$ & & $D K \rightarrow E N F($ tüfe $) \quad(M B)$ \\
\hline$D K \rightarrow E N F($ ötüfe $)(M B)$ & & $D K \rightarrow E N F($ ötüfe $)(M B)$ \\
\hline
\end{tabular}

Burada görüleceği gibi, 2003-2016 döneminde FAIZ'den ENF(üfe)'ye ve ENF(üfe)'den FAIZ'e olmak üzere karşılıklı doğrusal olmayan nedensellik ilişkisi vardır. Yani doğrusal olmayan nedensellik çift yönlüdür. Tüm analiz dönemi bir bütün olarak alındığında hem Siyasilerin söylemlerinin hem de Merkez Bankasının söylemlerinin geçerli olduğu görülmektedir. Ancak alt dönemlere bakıldığında 2011 yılındaki kırılmadan sonra faizin enflasyonla hiçbir nedensellik bağının kalmadığı görülmüştür. Bu ilişki, kırılma öncesinde her üç enflasyon için de geçerli iken 2011 sonrasında aralarında bir nedensellik bağının kalmadığı ortaya çıkmıştır.

Dolar kuru enflasyon ilişkisine baktığımız da ise tüm dönem ve alt dönemlerde sadece DK'dan ENF'e tek yönlü doğrusal olmayan nedensellik ilişkisinin olduğu ortaya çıkmıştır. Bu değişkenler için Merkez Bankasının söylemlerinin geçerli olduğu ifade edilebilir. 2003-2016 ve kırılma sonrası 2008:11-2016:03 arası dönemde DK'dan tüm enflasyonlara tek yönlü doğrusal olmayan nedensellik varken bu ilişki 2003-2008 kırılma öncesi dönemde sadece DK'dan ÖTÜFE enflasyonuna doğru gerçekleşmiştir. Bu dönemde döviz kurundaki değişmeler sadece çekirdek enflasyonda değişmelere neden olmuş, diğer tüfe ve üfe enflasyonunda değişmeye neden olmamıştır. DK'nun tüm enflasyonların nedeni olduğu bulgusuna ulaşılmıştır. Bu da tüm dönemlerde, özellikle de 2008 kırılmasından sonra döviz kurunun enflasyona geçirgenliğinin söz konusu olduğunu göstermektedir. Merkez Bankasının hükümete ve kamuoyuna yaptığı son açıklamada da, 2015 yılı enflasyon hedefinin tutturulamamasının temel nedeninin kurlar olduğunu belirtmiş olması da kırılma sonrası enflasyonun önemli sebebinin kurlar olduğu bulgusunu destekler niteliktedir.

\section{SONUÇ ve DEĞERLENDIRME}

Bu makalede, 2003-2016 analiz döneminde enflasyon ile faiz oranı ve enflasyon ile döviz kuru ilişkisi hakkında siyasilerin söylemi mi yoksa Merkez Bankası söylemi mi geçerli olduğu sorusuna cevap aranmıştır. Yapılan testler sonucunda faiz, dolar kuru ve enflasyon serilerinin durağan ancak doğrusal olmadığı belirlenmiş ve Diks-Panchenko doğrusal olmayan nedensellik testi uygulanmıştır. Analizler sonucunda her iki söylemin de geçerli olduğu dönemler olduğu gibi sadece bir söylemin geçerli olduğu dönemlerin olduğu görülmüştür.

Çalışmanın birinci önemli bulgusu, 2003-2011 döneminde enflasyon ile faiz oranı arasında çift yönlü nedensellik varken 2011'deki kırılma sonrasında bu ilişkinin ortadan kalktığıdır. İkinci önemli bulgu ise, 2008 yılı sonrasında döviz kurundan enflasyona nedenselliğin ortaya çıkışıdır. Bu da 2008 yılına kadar sadece döviz kurundan çekirdek enflasyona var olduğu görülen nedensellik ilişkisinin 2008 yılından itibaren döviz kurundan enflasyonun tüm tanımlarında geçirgenliğin arttığını ortaya koymaktadır.

Enflasyon-faiz oranı ve enflasyon-döviz kuru arasında yapılan nedensellik analizleri sonucunda elde edilen bulguların ekonometrik ve ekonomik olacak şekilde iki başlık altında toplanması uygun olacaktır:

\section{Ekonometrik olarak}

Türkiye için doğrusal olmamayı dikkate alıp nedensellik ilişkisini inceleyen bir çalışma olmaması ve çeşitli dönemler için yapılan nedensellik analizlerinin doğrusallık varsayımı altında yapılmış olması nedeni ile bu çalışmanın bulgularını direk karşılaştırma yapma olanağımız olmamıştır. Ancak bunlar arasından Doğan, Eroğlu ve Değer'in (2015) analiz dönemi (2003-2015) bu çalışmanın analiz dönemine 
(2003-2016) benzer olduğu enflasyon-faiz oranı arasındaki ilişki için karşılaştırma yapılmıştır. Doğrusal nedensellik analizi sonucunda enflasyondan faiz oranına tek yönlü nedensellik bulgusuna ulaşırlarken bu çalışmada faiz ve enflasyon(üfe) arasında çift yönlü nedensellik bulunmuştur.

$M B$ ve iktisatçıların enflasyonun temel göstergesi kabul ettikleri OTUFE'nin de nedensellik ilişkisine katıldığını gördük. Bu bulgu, önemli bir bulgudur; çünkü kısa vadeli arz ve talep koşullarından daha az etkilendiği ve merkez bankalarının para politikaları yoluyla kontrol edebileceği fiyatları gösterdiği için bazı ekonomistler tarafından gerçek enflasyon olarak değerlendirilmektedir.

\section{İktisadi olarak}

Döviz kuru için 2008 krizi ve faiz için 2011 krizi sonrasında Merkez Bankasının politikalarını değiştirdiği ortaya konulmuştur. Genel olarak döviz kurunun enflasyon geçirgenliğinin analiz döneminde, özellikle de 2008 krizi sonrasında arttığını söyleyebiliriz. Merkez Bankası, faizi kontrol altında tutarak gerçekleştirdiği sıkı para politikasının enflasyondan ziyade kuru kontrol altına almak amaçlı olduğu ifade edilebilir. Bundan sonraki dönemde de yapısal değişiklikler gerçekleştirilmedikçe faiz oranı aracı ile döviz kuru kontrolünün devam edeceğini söyleyebiliriz.
Merkez bankasının 2011 yılından itibaren döviz kurunu da izlemeye alması da bu bulgumuzu destekler niteliktedir.

M.B. Yeni Başkanı Çetinkaya: "Önemle vurgulamak isterim ki, önümüzdeki dönemde para politikası duruşu enflasyon görünümüne bağlı olmaya devam edecektir. Türkiye Cumhuriyet Merkez Bankası olarak, enflasyon beklentilerini, fiyatlama davranışlarını ve enflasyonu etkileyen diğer unsurlardaki gelişmeleri dikkate alarak para politikasındaki sıkı duruşumuzu gerekli gördüğümüz süre boyunca koruyacağız." diyerek bunun sinyalini vermiştir.

Bulgular, sadece merkez bankası veya politika koyuculara değil, aynı zamanda firmalar ve hanehalkı içinde önemlidir. MB ve politika koyuculara, anılan ekonomik değişkenler arasındaki ilişkiyi nasıl ele almaları gerektiği konusunda yol gösterici olacaktır. Özellikle döviz kurundan enflasyona geçirgenliğin yüksek olması, sadece yetkilileri değil, firmaları ve hanehalkını da ilgilendirmektedir. Firmalar açısından ele alındığında ithal edilen girdilerin yurtiçi fiyatları değişecek, firmaların üretim maliyetlerine etki edecek ve gelecek davranışları hakkındaki beklentileri etkiyecektir. Hanehalkı açısından ise, onların tüketim kararlarını bozacaktır.

\title{
SON NOTLAR:
}

\begin{abstract}
'Sayın Cumhurbaşkanı́nın söylemleri Yeni-Fisher'ci modellere dayanmakta olup bu teori, Türkiye'deki faiz-enflasyon tartışmasında böylece kendine yer bulmuştur. Bu görüşü destekleyen çok sayıda iktisatçı olmasına rağmen Yeni-Fisher'cilere karşı olanların buna karşı önemli eleştirileri vardır; "bu yaklaşımla sonuca ulaşmak için bir uzun-dönem dengesinden başka bir uzun-dönem dengesine sıçramak ve dengesizlik durumlarının yol açacağı istikrarsızığı yok saymak gerekiyor." TCMB'deki iktisatçıların Yeni-Fisher'ci modeller ilgili yorumlarına da TCMB Eski Başkanı Başı̧ı́nın geçtiğimiz Haziran ayında yaptığı Bakanlar Kurulu sunumunda, Yeni-Fisherci modelden türetilmiş bir grafik gösterilerek yapılan açıklamada rastlıyoruz: "Enflasyonu artıracak bir şok geldiğinde, ben eğer sert bir faiz indirimine gitmiş durumda olursam, enflasyon oranı kısa vadede kontrol edemediğim bir şekilde artabilir. Oysa sıkı politikamda ısrarcı olursam, yakın gelecekte enflasyon oranı düşerken faizleri yavaşça indirme şansını yakalayabilirim."

ii Tartışmanın olduğu dönemde MB'nın çeşitli tarihlerde gerçekleştirdiği faiz indirimleri ve bunun enflasyon ve dolar üzerindeki etkilerine bir göz atıldığında: 2015 Ocak ayında faiz oranı \%7,75 oranında iken 2016 Ocak ayında faiz oranı \%7,50 olarak gerçekleştiğinde yani faiz oranı azalırken enflasyon ve dolar kurundaki değișiklikler ise 2015 yılı Ocak ayı yıllık enflasyon oranın \%7,24, Dolar 2,29 iken; 2016 Yılı Ocak ayında yıllık enflasyon oranının \%8.81 Doların ise 3,04 olarak gerçekleştiği görülmektedir. Sonuç olarak faiz oranlarında azalma söz konusu iken enflasyon oranında ve dolar kurunda önemli artışın olduğu gözlemlenmiştir.

iii Dalgalı kur rejimi uygulayan açık bir ekonomide paranın iç değeriyle dış değeri birlikte hareket eder. Yani enflasyon oluşmuşsa paranın dış değeri de düşer ya da paranın dış değeri düşmüşse enflasyona yol açar. Bu durumda tek çözüm faizi yükselterek dış finansman için yeniden çekim alanı yaratmaya çalışmaktır. Böylece yabancı kaynaklar içeri çekilmiş ve kurlar düşürülmüş, enflasyon da denetim altına alınmış olur.

iv Durağan seriler için Kurtosis değerleri; DLDK için 7.78, DLFAIZ için 9.43, ENF(tüfe) için 3.32, ENF(üfe) için 4.40 ve ENF(otüfe) için 2.99 olarak hesaplanmıştır.
\end{abstract}

\section{KAYNAKÇA}

Ağayev, S. (2011) “Azerbaycan'da Fiyatlar Genel Düzeyi ve Döviz Kuru İlişkisi" H.Ü. Iktisadi ve Idari Bilimler Fakültesi Dergisi, 29(1): 1-19.
Altınay, G. (1996) “Exchange Rates and Domestic Prices: A Test of Causality" Dokuz Ey/ül Üniversitesi IIBBF Dergisi, 11:175-190. 
Awomuse, B. O. ve Alimi, S. R. (2012) "The Relationship Between Nominal Interest Rates and Inflation: New Evidence and Implication for Nigeria" Journal of Economics and Sustainable Development, 3(9):158-164.

Atgür, M. ve Altay O.N. (2015)“Enflasyon ve Nominal Faiz Oranı İlişkisi: Türkiye Örneği (2004-2013)" Yönetim ve Ekonomi Celal Bayar Üniversitesi IIBBF Dergisi, 22(2).

Akıncı, M. ve Yılmaz, Ö. (2016) "Enflasyon-Faiz Oranı Takası: Fisher Hipotezi Bağlamında Türkiye Ekonomisi Iç̧in Dinamik En Küçük Kareler Yöntemi" Sosyoekonomi, 24(27):33-55.

Bayat, T. (2012) “Türkiye'de Fisher Etkisinin Geçerliliği: Doğrusal Olmayan Eşbütünleşme Yaklaşımı" Erciyes Üniversitesi iktisadi ve Idari Bilimler Fakültesi Dergisi, 38:47-60.

Booth, G. G. ve Ciner, C. (2001) "The Relationship Between Nominal Interest Rates and Inflation: International Evidence", Journal of Multinational Financial Management, 11:269-280.

Brock, W. A., Dechert, W. Ve Scheinkman, J. (1987) "A Test For Independence Based On The Correlation Dimension" Working Paper, University Of Winconsin At Madison, University Of Houston, And University Of Chicago.

Christopoulos, D. K. Ve Leon-Ledesma, M. A. (2007) “ A Long-Run Non-Linear Approach To The Fisher Effect" Journal Of Money, Credit And Banking, 39(2-3):543-559.

Diks, C. Ve Panchenko, V. (2006) "A New Statistic And Practical Guidelines For Nonparametric Granger Causality Testing" Journal Of Economic Dynamics And Control, 30(9):1647-1669.

Doğan, B., Eroğlu, Ö. Ve Değer, O. (2016) "Enflasyon Ve Faiz Oranı Arasındaki Nedensellik İlişkisi: Türkiye Örneği". Çankırı Karatekin Üniversitesi IïBF Dergisi, 6:1-21.

Dickey, D. A. Ve Fuller, W.A. (1979) “Distributions OfThe Estimators For Autoregressive Time Series With A Unit Root" Journal Of The American Statistical Association, 74:427-31.

Enders, W. Ve Granger, C. W. J. (1998) “Unit Root Tests And Asymmetric Adjustment With An Example Using The Term Structure Of Interest Rates" Business And Economic Statistics, L6:304-311.

Fisunoğlu, M.H.Ve Çabuk, A.H. (1998) “Düşük Oranlı Ve Sürekli Kur Ayarlamalarının Enflasyon Üzerinde Etkisi" ODTÜ Gelişme Dergisi, 25(2):297-309.

Gözen, M.Ç., Koç, S. Ve Abasız, T. (2016) "Testing The Validity Of Exchange Rates Determination Approaches For Turkey" Marmara Üniversitesi Iktisadi ve Idari Bilimler Dergisi, 38(2):125-142.
Gül, E. Ve Ekinci, A. (2006) "Türkiye'de Enflasyon Ve Döviz Kuru Arasındaki Nedensellik İlişkisi: 1984-2003" Anadolu Üniversitesi Sosyal Bilimler Dergisi, 91-106.

Güven, E.T.A. Ve Uysal, D. ( 2013) “Türkiye'de Döviz Kurlarındaki Değişme Ile Enflasyon Arasındaki İlişki (1983-2012)" Akademik Araştırmalar Ve Çalışmalar Dergisi, 5(9).

Işık, N., Acar, M,Ve IŞıK, H. B. (2004) "Enflasyon Ve Döviz Kuru ilişkisi: Bir Eşbütünleşme Analizi." Süleyman Demirel Üniversitesi Iktisadi Ve Idari Bilimler Fakültesi Dergisi, 9.2.

Kapetanios, G., Shin, Y. Ve Snell, A. (2003) “ Testing For A Unit Root In The Nonlinear STAR Framework" Journal OfEconometrics, 112(2):359-379.

Kara, H., \& Öğünç, F. (2008). "Inflation Targeting and Exchange Rate Pass-Through: The Turkish Experience." Emerging Markets Finance and Trade, 44(6): 52-66.

Kholdy, S. Ve Sohrabian, A. (1990) “Exchange Rates And Prices: Evidence From Granger Causality Tests", Journal Of Post Keynesian Economics, 13(1). 71- 78.

Kim, K.H. (1998) “US Inflation And The Dollar Exchange Rate: A Vector Error Correction Model", Applied Economics, 30:613-619.

Koch, P.D., Rosensweig, J.A. Ve Whitt, J. A. (1988) "The Dynamic Relationship Between The Dollar And US Prices: An Intensive Empirical Investigation", Journal Of International Money And Finance, 7:181-204.

Koç S, T. Abasız (2012) "Türkiye ve Seçili AB Ülkeleri Açısından Enflasyon Sürekliliğin Analizi" Doğuş Üniversitesi Dergisi, 13 (1), 102-113

Koç, S., Beşer, M.K., (2006) “Testing Nonlinearity in the Rate of Current Account Deficit to GNP:TURKEY Case" Journal of Management and Education, 2(2): 67-73

Lanne, M. (2006) "Nonlinear Dynamics Of Interest Rate And Inflation" Journal Of Applied Econometrics, 21(8): 1157-1168.

Rossi, M. M. Ve Leigh, D. M. (2002) “Exchange Rate PassThrough In Turkey" No. 2-204. International Monetary Fund.

Manning, L. M. Ve Andrianacos, D. (1993) "Dollar Movements And Inflation: A Cointegration Analysis" Applied Economics, 25(12), 1483-1488.

Maswan, J. C. (2006) "Granger Non-Causality Test Of The Inflation-Exchange Rate In The Democratic Congo" WP03/06, 1-12.

Mercan, M. (2013) “Enflasyon Ve Nominal Faiz Oranları Arasındaki Uzun Dönem Illişkinin Fisher Hipotezi Çerçevesinde Test Edilmesi: Türkiye Örneği"Atatürk 
Üniversitesi Iktisadi Ve Idari Bilimler Dergisi, 4(27), 368384.

Mihaljek, D. Ve Klau, M. (2001) "A Note On The PassThrough From Exchange Rate And Foreign Price Changes To İnflation İn Selected Emerging Market Economies" BIS Papers, 8: 69-81.

Million, N. (2004) "Central Bank's Interventions And The Fisher Hypothesis: A Threshold Cointegration Investigation" Economic Modelling, 21(6), 1051-1064.

Maki, D. (2005) "Asymmetric Adjustment Of The Equilibrium Relationship Between The Nominal Interest Rate And Inflation Rate" Economics Bulletin, 3(9), 1-8.

Nourzad, F. (1997) "The Short-And Long-Run Relationships Between The Dollar And Producer Prices In The U.S.", International Economic Journal, 11 (2):59-71.

Peker, O. Ve Görmüş, Ş. (2008)“Türkiye'de Döviz Kurunun Enflasyonist Etkileri"Süleyman Demirel Üniversitesi iktisadi Ve Idari Bilimler Fakültesi Dergisi, 13(2).

Rahman, M., Mustafa, M.Ve Bailey, E.R. (1996)“US Budget Deficits, Inflation And Exchange Rate: A Cointegration Approach", Applied Economics Letters, 3:365-368.

Rittenberg, L. (1993) “Exchange Rate Policy And Price Level Changes: Causality Tests For Turkey In The Post Liberalization Period", The Journal Of Development Studies, 2(2):245-259.

Şimşek, M. Ve Kadılar, C. (2006) “Fisher Etkisinin Türkiye Verileri Ille Testi" Doğuş Üniversitesi Dergisi, 7(1):99-111.

Siregar, R.Y. (1999) "Real Exchange Rate Targeting And Inflation In Indonesia:Theory And Empirical Evidence" Southern Economic Journal, 61(4):991-1005.

Sollis, R. (2004) "Asymmetric Adjustment And Smooth Transitions: A Combination Of Some Unit Root Tests" Journal Of Time Series Analysis, 25(3), 409-417.
Tarı, R. (1997) “Türkiye'de Enflasyon, Faiz Ve Döviz Kuru Arasındaki Nedensellik illişkileri" Kocaeli Üniversitesi IïBF Dergisi, 1:225-231.

Telatar, F. Ve Telatar, E. (2003) “The Relationship Between Inflation And Different Sources Of Inflation Uncertainty In Turkey" Applied Economic Letters, 10(7):431-436.

Terzi, H. Ve Zengin, H. (1996)“Türkiye'de Kur Ve Enflasyon Arasındaki Nedensellik İlişkisi Üzerine Bir İnceleme", MÜ Istatistik Ve Ekonometri Araştırma Ve Uygulama Merkezi Dergisi, 1: 3-15.

Teker, D., Alp, E. A.Ve Kent, O. (2012). “Long-Run Relation Between Interest Rates And Inflation: Evidence From Turkey" Journal Of Applied Finance \& Banking, (6)2: 4154.

Turgutlu, E. (2004) "Fisher Hipotezinin Tutarlılığının Testi: Parçalı Durağanlık Ve Parçalı Koentegrasyon Analizi" Dokuz Eylül Üniversitesi İkt. Ve İ. Bil. Fak. Dergisi, 2(19): 55-75.

Yamak, R. Ve Abdioğlu, Z. (2007) "Fisher Hipotezinin Testi: Güçlü Ve Zayıf Form" Kahramanmaraş Sütçü Imam Üniversitesi Sosyal Bilimler Dergisi, 4(1-2):1-9.

Yamak, N. Ve Tanrı̈ver, B. (2007) “Türkiye'de Nominal Faiz Oranı-Genel Fiyat Düzeyi Illişkisi: Gibson Paradoksu" 8. Türkiye Ekonometri Ve İstatistik Kongresi, İnönü Üniversitesi, Malatya

Yanar, R. (2008) “Gelişmekte Olan Ülkelerde Döviz Kuru Rejim Tercihinin Makro Ekonomik Performans Üzerine Etkileri" Gaziantep Ünv. Sosyal Bilimler Dergisi,7(2):255270.

Weidmann, J. (1997) “New Hope For The Fisher Effect? A Re-Examination Using Threshold Co-Integration" University Of Bonn Discussion Paper, B-385. 
